\title{
ASPECTOS TEÓRICOS-METODOLÓGICOS SOBRE O USO DO CONCEITO DE SISTEMAS EM CLIMATOLOGIA
}

\author{
Lucas Moreira Sales de Oliveira ${ }^{\text {(a) }}$ \\ (a) Instituto de Geociências, Universidade Federal de Minas Gerais, lucasforense@ yahoo.com
}

Eixo: Climatologia em diferentes níveis escalares: mudanças e variabilidades

\begin{abstract}
Resumo
A utilização da modelagem de sistemas em climatologia elevou consideravelmente a compreensão que temos sobre os diversos climas da Terra e como eles se interagem e evoluem no tempo. Existe, contudo, uma preocupação de caráter teórico em caracterizar o clima propriamente como um sistema, sem diminuir oconteúdo que este conceito deve carregar. Este trabalho tem como objetivo levantar reflexões sobre este aspecto da climatologia geográfica, trazendo o arcabouço teórico sobre os sistemas de Ervin Laszlo (1996) e assumindo o discurso do aquecimento global como exemplo prático na discussão. Os resultados apontam, de forma preliminar, para uma utilização automatizada do conceito de sistemas no âmbito do discurso que será analisado.
\end{abstract}

Palavras chave: sistemas, climatologia geográfica, aquecimento global

\section{Introdução}

Alguns termos ou conceitos no âmbito das ciências contemporâneas tornaram-se tão universais que, como resultado de um uso repetitivo, automático e até inconsciente, acabaram por perder parcial ou completamente o seu significado. É o caso do emprego do conceito de "sistemas" dentro das mais variadas vertentes de pensamento e investigação na ciência geográfica incluindo, por consequência, a climatologia. Este artigo, como fruto de uma reflexão teórica sobre o conteúdo do conceito "sistemas", pretende uma aproximação, da maneira breve que o espaço aqui nos dispõe, dos maus usos e das potencialidades do referido termo dentro das pesquisas em climatologia geográfica. O que pretende-se demonstrar ao fim da discussão é que o vicioso uso do conceito de sistemas dentro de pesquisas em climatologia pode vir a causar a corrosão de seu conteúdo, resultando em perda de informação, encobrimento de interpretações latentes e até mesmo a disseminação de falácias lógicas.

A ciência geográfica adotou a visão sistêmica de tal forma universal que são poucas as reflexões feitas ao se empregar o termo: sistema urbano, sistema geomorfológico, sistema fluvial, sistema ecológico, sistema climático. Até mesmo uma derivação do termo - o geossistema (SOTCHAVA, 1977) - foi introduzida na literatura, mais ou menos aos moldes dos ecossistemas dos biólogos. Pode-se dizer, com poucas chances de incorrer em erros, que o uso dos sistemas se tornou automático dentro da literatura geográfica. Mas o 
que este conceito agregou, de fato, aos estudos dessa ciência? A resposta não aparece tão clara. Tomando a climatologia como suporte de exemplos, pode-se de imediato supor que o clima da Terra, que compreende as interações da atmosfera com a superfície e é sustentado por complexos intercâmbios de energia e matéria nos mais variados níveis escalares, não poderia ser melhor descrito do que como um sistema. De fato, não há como negar a potencialidade da modelagem sistêmica da realidade em descrever as propriedades dos climas. Enormes avanços de interpretação da realidade climática de nosso planeta foram alcançados devido à substituição da visão clássica de mundo (em que, por exemplo, os atributos do clima como temperatura, umidade relativa do ar, direção dos ventos, radiação, entre outros, eram estudados isolados um dos outros, formando conhecimentos fragmentados e dispersos). Por outro lado, quando se utiliza a visão sistêmica para descrever um fenômeno natural, como o fenômeno climatológico, deve-se arcar com mais do que uma vaga noção de totalidade ou de interações entre as partes. Os sistemas naturais se diferem de outros tipos de sistemas, e essas diferenças muitas vezes não são respeitadas.

O que se pretende com este trabalho é levantar uma discussão teórica com relação ao uso da visão sistêmica em climatologia, não no sentido de negar a sua aplicabilidade imediata na investigação do clima, mas sim em dar um passo atrás e apontar quais são os critérios que devem ser levados em conta quando modelamos um fenômeno natural como o clima através de uma visão holística como a sistêmica. Em uma revisão breve da literatura sobre o tema, podemos apontar trabalhos que hoje são vistos como clássicos dentro da geografia, assim como a obra de Monteiro (1975; 1978; 1991; 2000) e de Christofoletti (1979) e outros que, mais recentemente, desdobraram os aspectos teóricos da visão sistêmica dos fenômenos geográficos em geral, como Vicente e Perez Filho (2003) e dos fenômenos climatológicos em especial, como Jardim (2007) e Caracristi (2007). Todas essas obras serviram de lastro teórico para a presente investigação.

\section{Metodologia de trabalho}

Será resgatado parte do arcabouço teórico contido na obra The systems view of the world: a holistic vision for our time, de Ervin Laszlo (LASZLO, 1996), um distinto expoente da teoria e da filosofia dos sistemas. Desta obra serão extraídas quatro proposições fundamentais que o conceito "sistema" (em especial os sistemas naturais, do qual o clima da Terra faz parte) deve carregar em seu conteúdo para não ser utilizado de forma leviana ou apenas por modismo científico. Para contextualizar estes aspectos teóricosconceituais à climatologia, serão levantadas discussões sobre a aplicabilidade do termo no discurso do aquecimento global, tema recorrente nos noticiários e no âmbito acadêmico de forma geral. 
O eixo de análise adotado será baseado na tríade conceitual escala - hierarquia - sistemas e suas interconexões, e que os fenômenos climatológicos serão abordados dentro de um esquema teórico que envolve múltiplas dimensões espaciais e temporais.

\section{Embasamento teórico}

Para melhor compreensão do que será exposto cabe uma breve elucidação do que será tratado como sistema, em geral, e sistema natural em especial (do qual o sistema climático faz parte). Para fins de caracterização prática, o conceito geral de sistema, ou visão sistêmica, é melhor definido quando comparado à sua imagem imediatamente antagonista: a visão reducionista. Enquanto esta última busca encontrar a homogeneidade implícita na diversidade fazendo referência a uma substância compartilhada em comum (assim como o átomo é a substância comum compartilhada por toda a matéria) a visão sistêmica busca encontrar essa característica comum em termos de aspectos de organização compartilhada dentro de uma diversidade de elementos (LASZLO, 1996).

Pode-se dizer, portanto, que um sistema é definido como a expressão de características comuns de uma estrutura de elementos diversificados em integração que se organizam em várias totalidades funcionais. Uma analogia didática para o melhor entendimento do conceito de sistema foi apresentada por Laszlo de forma minuciosa, a qual espera-se o consentimento dos leitores em apresenta-la aqui conforme o original, em língua inglesa, para não haver deslizes ou vícios de tradução livre:

Reductionism is comparable to looking at a barn, a home, and an office building as so many structures erected of brick and concrete, disregarding their particular differences. The systems sciences look at them in terms of the organization of the materials which gives each structure its specific characteristic. They discover repeating patters in the organization, such as floors, doors, and windows, and evaluate these as so many variations on a common theme. But they do not hold that you can reduce a barn, a home, and a office building to sameness by taking them apart to individuals pieces of brick and concrete. Such reduction eliminates precisely that which is essential about each structure: the organization of the materials into variously functioning wholes (LASZLO, 1996, $p$. 17).

Os sistemas naturais, por sua vez, apresentam algumas invariâncias próprias, ou seja, características de organização gerais que são compartilhadas por todos os fenômenos ditos naturais e que os distinnguem daqueles que não são naturais (artificiais) ou que não são sistêmicos (Idem, 1996, p. 19). Cabe ressaltar que ao caracterizar um fenômeno como sistema natural não se diz tudo sobre ele, mas se estabelece algum tipo de generalização que o correlaciona a um vasto grupo de sistemas de organização complexa na natureza, tais como o sistema geomorfológico ou o sistema biológico. Nas palavras de Lazlo (1996, p. 20), é o mesmo tipo de generalização que é feita ao categorizar, por exemplo, uma pessoa como um ser 
humano ou como uma coisa viva (sendo os tipos de invariâncias especificas de maior generalização do primeiro caso para o segundo).

Em resumo, pode-se dizer que a abrangência do termo "sistema natural" diz menos sobre as peculiridades individuais de um fenômeno e mais do que ele compartilha com outros fenomenos naturais. Dessa forma, se o que se deseja é saber o que há de fundamentalmente importante sobre um fenômeno (climatológico, por exemplo), cabe defini-lo como um sistema natural. Posteriormente, se existir o questionamento do que separa o fenomeno climatológico de um outro sistema natural (o sistema biológico, por exemplo), será preciso definir os critérios que se aplicam, no primeiro caso, aos sistemas inorgânicos ou físicos e, no segundo caso aos sistemas orgnânicos. Neste artigo o objetivo principal foi destacar o primeiro nível de generalização dos sistemas naturais, ou seja, aquele que todos eles têm em comum.

\section{Resultados e Discussão}

A primeira proposição descrita por Laszlo que compreende uma das invariâncias organizacionais dos sistemas naturais complexos talvez seja a que mais frequentemente apareça quando este tema é tratado na literatura: natural systems are wholes with irreducible properties (LASZLO, 1996, p. 25). Esta proposição está relacionada à noção disseminada sobre os sistemas de que o todo é maior do que a soma de suas partes, de onde se deriva a existência de propriedades emergentes dos sistemas (MORIN, 2002). Esta proposição, apesar de sua aparência quase metafísica, carrega um sentido importante e diz muito sobre um aspecto fundamental sobre os sistemas naturais: a existência de uma estrutura formal (organizada) construída sobre a interdependência das partes que compõem o todo.

Quando se investiga o clima terrestre deve-se chegar, cedo ou tarde, à conclusão de que existem inúmeros fatores (latitude, distribuição de massas oceânicas e continentais, barreiras orográficas, massas de ar, centros de ação atmosférica, atividade solar, rotação/translação do planeta, urbanização, atividades vulcânicas, composição química da atmosfera, entre incontáveis outros) que, mediante suas relações em múltiplas escalas, controlam os atributos climatológicos (temperatura, umidade do ar, distribuição de chuvas, direção preferencial dos ventos, etc.). Os fatores podem ser considerados as "partes" do todo que se expressam pelas qualidades emergentes dos atributos ${ }^{1}$. Para caracterizar o clima da Terra (nos moldes do discurso do aquecimento global antrópico) de uma forma sistêmica que atendesse a primeira proposição, seria de se esperar que a característica emergente do todo (como, por exemplo, "temperaturas

\footnotetext{
${ }^{1}$ Existem outras possibilidades de interpretação, como por exemplo considerar que as partes do sistema são os elementos combinados com os fatores, enquanto as propriedades emergentes seriam as próprias características do clima analisado como o seu ritmo, sua variabilidade e até os impactos ambientais dele decorrente.
} 
mais quentes" ou "níveis dos oceanos mais elevados") seria irredutível às características de suas partes (ou de seus fatores isolados).

De forma geral, entretanto, não é o que ocorre. Como é possível notar em publicações como a de Mark Lynas (2009) e inúmeras outras sobre o aquecimento global, a visão sistêmica é abandonada e volta-se a examinar os dados de forma reducionista. A característica emergente das temperaturas mais altas, por exemplo, é reduzida à característica de uma das partes da totalidade climática, a saber a composição química da atmosfera (aumento dos níveis de $\mathrm{CO}_{2}$ ). Aqueles ditos ambientalistas e defensores do discurso do aquecimento global derivado das atividades antrópicas tendem a não acompanhar este raciocínio para as questões climáticas, mas se esquecem de que levantam a mesma bandeira da visão sistêmica de mundo para outros assuntos que chamam a atenção nas colunas sociais dos noticiários. A visão sistêmica superou, por assim dizer, aquela visão mecanicista e individualista das atividades cotidianas em que a acumulação de bens materiais, a cobiça e a competição eram promovidas e enaltecidas, dando lugar à preocupação com a informação e, portanto, com a educação, a comunicação e aos serviços sociais. A mesma visão sistêmica é utilizada para desconstruir o cenário eurocêntrico criado pela visão de mundo clássica, em que as sociedades ocidentais e industrializadas eram vistas como modelo de desenvolvimento e progresso, dando lugar a um cenário de igualdade multicultural.

A segunda proposição a ser analisada é a que diz que os sistemas naturais se mantêm em um ambiente em constante mutação - Natural systems maintain themselves in a changing environment (LASZLO, 1996, p. 30). Em termos gerais, esta característica do sistema natural se relaciona com sua capacidade de importar energia e/ou matéria e se manter em um estado de equilíbrio dinâmico (steady-state). Somente os sistemas abertos possuem essa propriedade. Os sistemas isolados, pelo contrário, são fadados ao colapso quando o seu suprimento de energia e/ou matéria se esgotar.

O clima da Terra é, sem dúvida, um sistema aberto em equilíbrio dinâmico. A Terra importa do Sol a energia necessária para manter seus processos (físico, químicos, biológicos, sociais, etc.) em funcionamento. Quando se diz que o clima da Terra se mantem, mesmo em condições de mudanças ambientais (como alterações na órbita terrestre ou períodos de maior ou menor atividade solar, por exemplo), não é de se esperar que as mesmas configurações permaneçam inalteradas. O que ocorre, de fato, é uma reorganização dos fatores que controlam o clima e, por consequência, uma alteração da maneira pela qual esses fatores se expressam no espaço (através dos atributos climáticos). A alteração da organização não leva o sistema ao colapso, mas sim para um novo patamar de organização. Os exemplos mais expressivos dessa propriedade do sistema climático são os períodos de glaciação e interglaciação, em 


$\begin{aligned} & \text { XVII Simpósio Brasileiro } \\ & \text { de Geografia Fisica Aplicada }\end{aligned}$
$\begin{aligned} & \text { I Congresso Nacional } \\ & \text { de Geografia Física }\end{aligned}$

que os fatores ambientais se alteram e, consequentemente, os atributos dos diversos climas da Terra se reorganizam de forma a manterem-se funcionais.

Cabe a ressalva que um sistema em equilíbrio dinâmico tem a sua própria resiliência às pressões externas. O sistema climático é particularmente resistente a perturbações de pequena ordem escalar (tanto espacial quanto temporal). As grandes reorganizações dos fatores e atributos climáticos, como os períodos de glaciação e interglaciação mencionados, são decorrentes de alterações de larga escala temporoespacial (fenômenos astronômicos, por exemplo). As reorganizações percebidas pela alteração de fatores em escalas inferiores (locais ou microclimáticas) estão na ordem do clima urbano, restrito a pequenas distâncias e curtos intervalos de tempo.

A terceira preposição diz que os sistemas naturais criam a si mesmos em resposta a auto criatividade de outros sistemas: Natural systems create themselves in response to self-creativity in other systems (LASZLO, 1996, p. 39). Desta proposição surgem duas considerações importantes a serem tratadas sobre os sistemas naturais: a auto criatividade e resposta a outros sistemas. A auto criatividade em sistemas naturais não é compreendida em termos da visão clássica mecanicista (newtoniana) de mundo. Se o clima da Terra (como um sistema natural) for concebido como uma máquina que opera de forma determinista seguindo algumas leis predeterminadas, não existiria auto criatividade do sistema. Neste cenário, sendo conhecidas as leis (como as leis da termodinâmica) e as condições iniciais (valores de pressão, temperatura, dentre outros parâmetros), em qualquer ponto no espaço e no tempo (cronológico) seria possível determinar as condições do tempo meteorológico. Como ficou demonstrada pelo trabalho de Edward Lorenz, a realidade meteorológica não é tão simples assim (GLEICK, 1991). Tomado dois pontos de condições iniciais arbitrariamente tão próximos quanto desejado os padrões se distanciam cada vez mais, até que toda a semelhança desapareça, inviabilizando qualquer previsão (Figura 1).

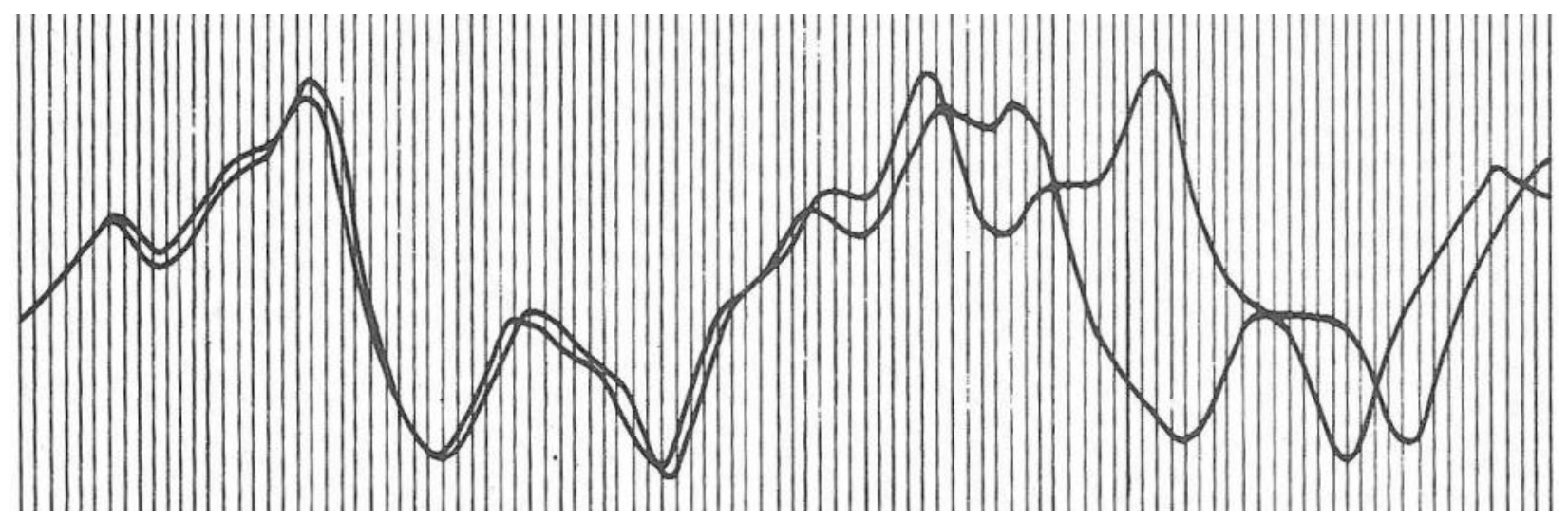

Figura 1 - Padrões de previsão de tempo elaborados por Edward Lorenz partindo de condições iniciais próximas (adaptado de GLEICK, 1991, p. 15) 
A noção de auto criatividade dentro de sistemas naturais como o sistema climático deriva dessa imprevisibilidade. Nenhum inverno é igual ao anterior e não será igual ao próximo, daí a capacidade do sistema climático de alterar a si mesmo e se manter em desenvolvimento dentro de seu equilíbrio dinâmico. Este fato está intimamente relacionado às dificuldades de modelagem numérica do sistema climático global, o que reflete em consideráveis dúvidas quanto à elaboração de provisões de cenários catastróficos para cinquenta ou cem anos no futuro como as realizadas pelo Painel Intergovernamental sobre Mudanças Climáticas (IPCC, sigla em inglês).

A segunda consideração a ser feita dentro da terceira proposição é a da resposta dos sistemas à auto criatividade de outros sistemas. Como os sistemas naturais são abertos, estão em contato constante, direta ou indiretamente, com os sistemas que os rodeiam. Naturalmente, portanto, o out put de um sistema pode servir de in put para outro. Como apontado por Laszlo (1996, p. 40-41) existe uma interdependência dos sistemas e, por isso, cada inovação em um deles impõe desafios ao outro, gerando assim um padrão de respostas ativas e não simplesmente uma cadeia passiva de causas e efeitos. É fácil perceber, portanto, que uma cidade, enquanto um sistema natural, produz out puts tais como poluentes e excesso de calor que irão servir imediatamente como in puts do sistema clima urbano, caracterizando a interdependência dos sistemas (respeitando as limitações escalares).

Por fim, a última proposição dos sistemas naturais diz que estes são interfaces coordenadas dentro da holarquia natural - Natural systems are coordinating interfaces in nature's holarchy. Em termos gerais, esta proposição aponta para o fato de não existirem sistemas isolados (mesmo que abertos) e sim uma superposição de sistemas sobre sistemas - ou ainda sistemas de sistemas, como destacado por Jardim (2007) - em uma estrutura multiescalar que atravessa desde o ambiente físico, passa pelo mundo orgânico e alcança ainda o domínio social ou supraorgânico, como prefere Laszlo (1996, p. 53).

Estes sistemas de sistemas estão organizados no que se assemelha a uma pirâmide holarquica, que segundo Laszlo possui a característica de ser composta por vários sistemas relativamente simples na base e alguns poucos sistemas complexos no topo (Idem, p.53). Entre esses extremos todos os sistemas naturais tomam parte intermediária, fazendo a ligação entre os níveis mais simples até os mais complexos. Eles são, portanto, "todos" em relação a suas partes, e partes em relação ao "todo" de maior nível.

O sistema climático apresenta esse aspecto na medida em que os fatores que controlam os atributos do clima são identificados eles próprios como sistemas. A geomorfologia, fator de grande importância para o clima, é em si um sistema com suas próprias características, dinâmica e auto-criatividade. Existem, entre esses sistemas, constante troca de matéria e energia, garantindo uma interface de coordenação e interação entre eles. Cada um assume um papel dentro da holarquia natural, que em conjunto com os demais 
sistemas (ecológico, social, dentre tantos outros) representam um modelo total da realidade que conhecemos. Como já foi ressaltado, essa noção de interação das diversas partes do todo geralmente não acompanha o discurso do aquecimento global que deriva o aumento de temperatura da Terra das atividades humanas.

\section{Considerações finais}

Com as breves reflexões teóricas sobre as características intrinsceas dos sistemas naturais, podemos alcançar algumas conclusões: (1) a utilização do conceito de sistemas em climatologia, em especial dentro do discurso do aquecimento global antrópico é, muitas vezes, desapropriado ou incompleto, tendo em vista o conteúdo que o conceito carrega em si; (2) a teoria dos sistemas aplicada em climatologia geográfica possui potencialidades ainda não exploradas, possivelmente devido à utilização do conceito de forma automatizada e outras dificuldades teóricometodologicas; (3) o que foi tratado neste trabalho não encerra as reflexões que devem ser feitas com relação ao uso da teoria dos sistemas em climatologia.

\section{Agradecimentos}

Este artigo é fruto de discussões no âmbito da pós-graduação em geografia do Instituto de Geociências da Universidade Federal de Minas Gerais e deve sincero agradecimento às contribuições do professor Carlos Henrique Jardim.

\section{Bibliografia}

CARACRISTI, I. A. Natureza complexa as poiésis climática: contribuições teóricas ao estudo geográfico do clima. Tese (Doutorado em Geografia) - Faculdade de Filosofia, Letras e Ciências Humanas, Universidade de São Paulo, São Paulo, 2007.

CHRISTOFOLETTI, A. Análise de sistemas em geografia. São Paulo: Hucitec: Editora da Universidade de São Paulo, 1979.

GLEICK, J. Caos: a criação de uma nova ciência. Trad. Waltensir Dutra. $4^{\text {a }}$ Ed. Rio de Janeiro: Campus, 1991.

JARDIM, C. H. Proposta de síntese climática a partir do comportamento térmico e higrométrico do ar em áreas urbanas. Tese (Doutorado em Geografia) - Departamento de Geografia - Instituto de Geociências Universidade Estadual de Campinas, Campinas, 2007.

LASZLO, E. The systems view of the world: a holistic vision for our time. New Jersey: Hampton Press Inc., 1996. $103 \mathrm{p}$.

LYNAS, M. Seis graus: o aquecimento global e o que você pode fazer para evitar uma catástrofe. Rio de Janeiro: Editara Zahar, 2009.

MONTEIRO, C. A. F. Teoria e Clima Urbano. Tese (Livre Docência) - Faculdade de Filosofia, Letras e Ciências Humanas, Universidade de São Paulo, São Paulo, 1975. 
MONTEIRO, C. A. F. Derivações antropogênicas dos geossistemas terrestres no Brasil e alterações climáticas: perspectivas urbanas e agrárias ao problema da elaboração de modelos de avaliação. In: I SIMPÓSIO A COMUNIDADE VEGETAL COMO UNIDADE BIOLÓGICA, TURÍSTICA E ECONÔMICA, 1978, São Paulo. Anais... São Paulo: Academia de Ciências do Estado de São Paulo, 1978.

MONTEIRO, C. A. F. Clima e excepcionalismo: conjecturas sobre o desempenho da atmosfera como fenômeno geográfico. Florianópolis: Editora da Universidade Federal de Santa Catarina, 1991.

MONTEIRO, C. A. F. Geossistemas: a história de uma procura. São Paulo: Contexto, 2000.

MORIN, E. O método 1: a natureza da natureza. Trad. Ilana Heineberg. Porto Alegre: Editora Sulina, 2002.

SOTCHAVA, V. B. O estudo de geossitemas. São Paulo: Instituto de Geografia USP (Métodos em Questão, 16), 1977.

VICENTE, L. E; PEREZ FILHO, A. Abordagem sistêmica em geografia. Geografia, Rio Claro, v. 28, p. 323-344, set./dez. 2003. 